\title{
A LEGITIMIDADE DEMOCRÁTICA DA JURISDIÇÃO CONSTITUCIONAL E AS AUDIÊNCIAS PÚBLICAS ${ }^{1}$
}

\section{THE DEMOCRATIC LEGITIMACY OF THE JUDICIAL REVIEW AND THE PUBLIC HEARINGS}

Raphael Marcelino de Almeida Nunes Doutorando em Direito pela Universidade de São Paulo ("USP"). Mestre e Bacharel pela Universidade de Brasília ("UnB"). Professor de Direito Civil e de Direito Constitucional pelo Instituto Brasiliense de Direito Público ("IDP"). Advogado. Rio de Janeiro/RJ. E-mail: raphaelmanunes@gmail.com

RESUMO: $O$ artigo trata do instituto das audiências públicas sob a perspectiva de análise de sua dupla função, qual seja, a de suprir déficits epistêmicos e a de garantir a participação da sociedade civil e de instituições interessadas nos debates realizados na Suprema Corte. A análise tem por objetivo testar a hipótese de que o referido instituto, no cumprimento dessa dupla função, poderia garantir a legitimidade democrática da jurisdição constitucional para tomada decisões em relação a questões sensíveis de natureza política.

PALAVRAS-CHAVE: Direito constitucional - jurisdição constitucional - audiências públicas - democracia - hermenêutica constitucional

\begin{abstract}
The object of this article is the analysis of the institute of public hearings from the perspective of its dual function: to fulfill epistemic deficits; and to ensure the participation of civil society and institutions interested in the debates held in the Supreme Court. The purpose of the analysis is to verify the validity of the hypothesis that the
\end{abstract}

\footnotetext{
${ }^{1}$ Artigo recebido em 10/03/2019 e aprovado em 24/07/2019.
} 
fulfillment of this dual function could guarantee the democratic legitimacy of the judicial review to decide sensitive political questions.

KEY WORDS: Constitutional law; Judicial review; Public hearings; Democracy; Constitutional interpretation.

\section{Introdução}

Tema dos mais antigos e ainda atuais do Direito Constitucional se refere à legitimidade democrática da jurisdição constitucional. Desde o advento do instrumento do judicial review, no âmbito do sistema norte-americano, a partir do célebre caso Marbury v. Madison, os constitucionalistas daquele país discutem as complexas relações entre as questões políticas e o papel do Judiciário.

Ainda naquela oportunidade, o Justice Marshall em seu voto condutor, possivelmente antevendo discussões a respeito da legitimidade da nova função atribuída à Suprema Corte, procurou estabelecer o limite de atuação do órgão ao asseverar que "questions, in their nature political, or which are, by the constitution and laws, submitted to the executive, can never be made in this court".

Trata-se, à toda evidência, de declaração francamente contraditória - para dizer o mínimo - com a própria conduta da Suprema Corte ao decidir, então, pela possibilidade de se submeter leis regularmente aprovadas pelo legislativo ao crivo do Judiciário, ainda que não houvesse qualquer previsão explícita no texto constitucional a esse respeito.

Desde então, a Suprema Corte e os constitucionalistas norte-americanos se desafiam a estabelecer os critérios que deveriam nortear, de forma apriorística, o entendimento acerca de quais atos poderiam e quais não poderiam ser submetidos ao controle de constitucionalidade por parte daquele tribunal.

A esse respeito, Louis Michael Seidman² argumenta que, ao contrário do que asseverado pelo Justice Marshall, não seria possível compreender o judicial review exercido

\footnotetext{
${ }^{2}$ SEIDMAN, Louis Michael, The Secret Life of the Political Question Doctrine, The John Marshal Law Review, v. 37, p. 441-480, 2004.
} 
no âmbito da jurisdição constitucional como uma função apolítica e não-discricionária. Diferentemente, é possível identificar diversas situações em que a Suprema Corte atua por critérios distintos daqueles extraídos do direito constitucional.

Nesse sentido, assevera o referido autor, que a jurisdição constitucional atua politicamente, não só ao tomar decisões contrárias àquelas exaradas pelos outros poderes, como também, ao não se posicionar, sob o fundamento da political question doctrine, em relação às determinadas questões. Em nosso sistema, os desafios relacionados à atuação do Poder Judiciário em questões políticas também têm sido verificados com particular gravidade.

De fato, é possível afirmar que o nosso texto constitucional, notadamente diante das previsões relacionadas a direitos e garantias de segunda e terceira geração, tem sido utilizado como parâmetro para o controle direto de políticas públicas por parte do Judiciário. Tal fenômeno tem se verificado, com extrema sensibilidade, especialmente no que concerne à garantia dos direitos à saúde, à educação e à moradia.

$\mathrm{Na}$ essência dos debates relacionados ao locus para se deliberar a respeito de determinadas questões políticas sensíveis vis-à-vis a legitimidade democrática das instituições imbuídas de tal mister, encontra-se, em nosso caso, o instrumento das audiências públicas, previsto na Lei 9.868/99.

De fato, como se explicitará mais adiante, o referido instituto é comumente referido em sua dupla função: (i) produção de informações necessárias para a solução do problema constitucional (suprir déficits epistêmicos) ${ }^{3}$; (ii) mecanismo de acesso e participação da sociedade civil na corte (legitimação democrática).

Essa perspectiva permite supor portanto, que se exitoso for o cumprimento dessa dupla função das audiências públicas, de um lado, permitir-se-á a participação de atores políticos, sociais, científicos, no processo deliberativo, e de outro, viabilizar-se-á o acesso às informações de que a Suprema Corte necessitaria para deliberar a respeito da questão constitucional sensível, o que consequentemente, resultaria na garantia da legitimidade democrática da jurisdição constitucional para resolver as referidas questões.

\footnotetext{
${ }^{3}$ LEAL, Fernando; HERDY, Rachel, Uma década de audiências públicas no Supremo Tribunal Federal (20072017)., Revista de Investigações Constitucionais, v. 5, n. 1, p. 331-372, 2018.
} 
Este artigo, portanto, tem por objetivo analisar o instituto das audiências públicas, a sua regulamentação, e a experiência da nossa jurisdição constitucional no seu emprego, de modo a testar a validade dessa hipótese à luz da sempre presente questão da legitimidade democrática da jurisdição constitucional.

Para tanto, inicialmente, será situado e delimitado o problema da legitimidade democrática da jurisdição constitucional para os fins pretendidos neste trabalho.

Em seguida, será analisada a origem dogmática do instituto com a apresentação dos fundamentos doutrinários estrangeiros e nacionais que permitiram o seu desenvolvimento. Nesse contexto, desenvolver-se-á a necessária problematização acerca da efetividade das normas vigentes para o adequado cumprimento das funções a que se propõem.

Por fim, será apresentada a conclusão que - desde já se adianta - se estabelece no sentido de reconhecer uma dissociação entre os fins pretendidos e os resultados efetivamente alcançados. Ou seja, concluir-se-á que as audiências públicas, na prática, podem não viabilizar, propriamente, a participação popular no processo decisório; não, necessariamente, qualificam o debate com as questões informativas pertinentes; e consequentemente não garantem a almejada legitimidade democrática para jurisdição constitucional.

\section{Breves notas sobre o déficit de legitimidade democrática da jurisdição constitucional}

Robert Dahl esclarece que uma decisão a respeito de políticas públicas seria aquela que representa uma escolha entre alternativas em relação às quais há, ao menos inicialmente, alguma incerteza ${ }^{4}$.

É necessário reconhecer que a jurisdição constitucional constitui um elemento relevante na produção de decisões de natureza política. Ao promover o judicial review, portanto, a Suprema Corte atua, efetivamente, como instituição apta a interferir significativamente em decisões públicas de caráter político.

\footnotetext{
${ }^{4}$ DAHL, Robert A, Decision-making in a democracy: the Supreme Court as a national policy-maker., Journal of Public Law, v. 1, p. 279-295, 1957.
} 
Alerta o referido autor, no entanto, que a Suprema Corte, no exercício de tais poderes, atua com fundamento em uma ficção de que as decisões por ela prolatadas não seriam decorrentes de influências de natureza política, mas, sim, do desenvolvimento de argumentação jurídica limitada ao disposto pelo direito vigente. Essa ficção, a rigor, constitui o cerne da legitimidade de sua atuação decisória.

Nesse contexto, e partindo da premissa de que a Suprema Corte, efetivamente, atua politicamente, Robert Dahl problematiza a atuação desse tribunal em um regime democrático ao se deparar, no exercício de sua atuação, com a necessidade de escolher determinados grupos sociais a serem favorecidos, em detrimento de outros, pela decisão política tomada.

À problematização formulada, o referido autor responde, com fundamentos empíricos colhidos na experiência constitucional norte-americana, que o tribunal, em boa parte de suas decisões, exerce poderes em consonância com as lideranças políticas que detêm o poder político. Mais enfaticamente, defende que a Suprema Corte assume um papel essencial no âmbito da aliança política então dominante ${ }^{5}$.

Em outras palavras, Robert Dahl procura desconstruir o lugar comum consubstanciado na compreensão de que as cortes constitucionais atuam em defesa dos direitos de minorias supostamente oprimidas por maiorias tirânicas. Diferentemente, a análise realizada pelo referido autor indica que a Suprema Corte, bem estabelecidas as forças políticas dominantes, atua em alinhamento com o posicionamento majoritário. Assevera, aliás, o autor em questão que, sozinha, a Corte é praticamente desprovida de poder para afetar o curso das políticas nacionais. Assim, na ausência de concordância substancial com essa aliança, uma tentativa por parte da Corte de realizar política pública por si só resulta em desastres, como aquele verificado no caso Dred Scott.

A propósito do tema, é interessante notar que Jeremy Waldron estabelece que a defesa do judicial review é articulada, primordialmente, em torno dos argumentos formulados na ideia da proteção garantida pela Suprema Corte contra eventual desvio tirânico por parte das

\footnotetext{
${ }^{5}$ Ibid.
} 
maiorias. Nesse sentido, o judicial review serviria como medida protetora contra patologias legislativas 6 .

Ocorre que, como visto, as conclusões de Robert Dahl, todavia, demonstram que, se verdadeiras, não se poderá sustentar a legitimidade democrática da Corte Constitucional com base nesses argumentos, uma vez que é possível afirmar que seu papel é exercido no sentido de determinada maioria atualmente no poder, ou após certo tempo de seu exercício.

Jeremy Waldron, também partindo da premissa de que o judicial review envolve o exercício de poder político, objetiva questionar, sob a perspectiva de filosofia política, a legitimidade democrática da atuação das cortes constitucionais. A esse respeito, assevera que, no âmbito das instituições democráticas, é considerado como elemento essencial a presença de igualdade política ${ }^{7}$. Nesse aspecto, reside o fundamento principal de seu argumento, que, a rigor, revela, neste particular, as profundas raízes de seu pensamento neokantiano.

Interessante notar, a propósito, a diferença entre valores de processo e valores de resultado que Waldron desenvolve. As leis podem ser justas ou injustas. E é natural que existam discordâncias a respeito. Entretanto, o que deve ser prestigiado são os valores relacionados ao processo. Mais uma vez, demonstra-se a discordância de Waldron no que concerne a argumentos de caráter utilitarista, o que é próprio, como se afirmou anteriormente, do pensamento neokantiano.

Assim, para Waldron - é possível afirmar - decisão politicamente correta (ou democraticamente boa, a depender da perspectiva de análise) é aquela tomada com fundamento na liberdade democrática. Para reforçar essa percepção, Waldron embasa seus elementos de legitimidade democrática em valores como "igualdade política", "autonomia" e "liberdade de expressão/direito de ser ouvido". ${ }^{8}$

\footnotetext{
${ }^{6}$ WALDRON, J., The core of the case against judicial review., Yale Law Journal, v. 115, p. 1346-1360, 2005.

${ }^{7} \mathrm{Ibid}$.

${ }^{8}$ In politics, the most familiar process-related reasons are those based on political equality and the democratic right to vote, the right to have one's voice counted even when others disagree with what one says. (Waldron, 2005, p. 1373)
} 
Não por outra razão, Waldron destaca a riqueza das argumentações desenvolvidas nas casas legislativas de países em que não há o judicial review, quando se está a debater sobre questões políticas importantes, como o direito de aborto ${ }^{9}$.

A propósito, no que concerne às discussões relativas ao aborto, verifica-se, no Brasil, que o ambiente para a formulação dos argumentos relativos a princípios morais, científicos, políticos e as questões pragmáticas relacionadas ao tema foi transferido - de forma irrefletida - para o Supremo Tribunal Federal, por força da audiência pública convocada pela Ministra Rosa Weber na Arguição de Descumprimento de Preceito Fundamental nº 422. Nesse âmbito se colocam em um mesmo patamar de validade, argumentos de caráter acadêmico, religioso, histórico ou político. O STF seria realmente o locus para esse tipo de debate?

É inconteste que no processo de desenvolvimento dos direitos constitucionalmente previstos há discordâncias quanto ao alcance da Constituição. Ou seja, o texto constitucional não é exauriente o suficiente para permitir que dissensos a respeito sobre determinados direitos sejam resolvidos por decorrência de procedimentos lógico-dedutivos. E nesse aspecto, portanto, reside o questionamento à atribuição aos juízes do papel de estabelecer a resolução final para as referidas discordâncias. Nesse sentido, assevera o referido autor:

\footnotetext{
"De maneira breve, a resposta é que a sociedade não se comprometeu com qualquer ponto de vista específico sobre o que um dado direito acarreta, então, quando cidadãos discordam sobre isso, não fica clara a razão pela qual conceder aos juízes o poder de decidir deveria ser entendido como manutenção de um pré-cometimento."10
}

Se é verdade a premissa exposta em Robert Dahl no sentido de que o processo decisório da suprema corte estaria em linha, de certo modo, com o stablishment político, a legitimidade democrática do judicial review se esvairia, haja vista que as "credenciais" daqueles que integram o processo decisório da suprema corte é, sob essa perspectiva de legitimidade, de nível bastante inferior, do ponto de vista de autodeterminação, liberdade e princípio majoritário, que caracteriza os processos democráticos.

\footnotetext{
${ }^{9}$ Ibid.

${ }^{10}$ Ibid.
} 
Afora isso, o modo de participação dos cidadãos no processo decisório no âmbito do judiciário não é tão legítimo quanto seria no âmbito de um legislativo em razoável funcionamento. Isso porque a participação em processos decisórios no âmbito do judiciário não garante a igualdade política entre os cidadãos.

Daí porque, conclui Waldron, o judicial review não seria o método adequado para a solução de discordâncias sobre direitos. O legislador ordinário seria mais adequado politicamente para fazê-lo, pois se encontraria em maior alinhamento em relação aos referidos valores que confeririam a necessária legitimidade democrática, notadamente à luz das razões relacionadas ao processo decisório.

Os fundamentos dos apontamentos de Waldron, como se verá adiante, vão constituir, exatamente, a essência dos anseios por promoção de maior participação pública no processo decisório no âmbito da jurisdição constitucional.

Nesse contexto, e em contraponto a essa percepção relativa ao judicial review, destacase o posicionamento de Luís Roberto Barroso, para quem "não é incomum nem surpreendente que o Judiciário, em certos contextos, seja melhor intérprete do sentimento majoritário" $" 11$.

Para o referido autor, o instrumento das audiências públicas vem assim, e em conjunto com outros fatores, legitimar a percepção de que "em algumas circunstâncias, juízes são capazes de representar melhor - ou com mais independência - a vontade da sociedade" ${ }^{\text {. }}$.

Diante disso, há que se indagar se o instituto das audiências públicas poderia resultar, efetivamente, na solução do déficit de legitimidade democrática por viabilizar a participação da sociedade civil e por estabelecer a conexão entre a Corte Constitucional e a Constituição material, a norma "vivida" no âmbito da sociedade - para se utilizar a expressão de Peter Haberle ${ }^{13}$.

\section{Dos fundamentos teóricos do instituto das audiências públicas}

\footnotetext{
${ }^{11}$ BARROSO, L. R., A razão sem voto: o supremo tribunal federal e o governo da maioria, Revista Brasileira de Políticas Públicas, v. 5, n. 2010, p. 23-50, 2015.

${ }^{12}$ Ibid.

13 HABERLE, P, Hermenêutica Constitucional - a sociedade aberta dos intérpretes da Constituição: contribuição para interpretação pluralista e procedimental da Constituição, DPU, v. 60, 2014.
} 
A discussão relativa à realização de audiências públicas no Supremo Tribunal Federal está vinculada à problematização da possibilidade de análise pela Corte dos fatos e prognoses, conforme alertara Gilmar Mendes, em seu precursor trabalho a respeito do tema em questão ${ }^{14}$.

Nesse contexto, é de se reconhecer que o instituto no Brasil foi declaradamente influenciado pelas contribuições de Peter Haberle, em sua célebre obra: Hermenêutica Constitucional - a sociedade aberta dos intérpretes da Constituição: contribuição para interpretação pluralista e procedimental da Constituição, obra essa que declaradamente constituiu os alicerces teóricos da ideia de criação do instituto entre nós ${ }^{15}$.

Defende o referido autor, que além daqueles imbuídos da competência para exercer a jurisdição constitucional, inúmeros outros atores vivem as normas que se extraem do texto constitucional. Por essa razão, não se poderia reconhecer algum tipo de monopólio da interpretação da Constituição ${ }^{1617}$.

Assim, a interpretação constitucional não é um evento exclusivamente estatal, seja do ponto de vista teórico, seja do ponto de vista prático. A ampliação do círculo de intérpretes, portanto, decorre da necessidade da integração da realidade no processo de interpretação. A norma não é uma decisão prévia, simples e acabada. Dessa forma, faz-se necessário indagar sobre os participantes no seu desenvolvimento funcional ${ }^{18}$.

O Juiz constitucional não interpreta a Constituição de forma isolada. São vários os participantes desse processo. A esfera pública pluralista desenvolve força normatizadora.

\footnotetext{
${ }^{14}$ MENDES, Gilmar Ferreira, Controle de Constitucionalidade: Hermenêutica Constitucional e Revisão de Fatos e Prognoses Legislativos pelo órgão judicial, Revista Jurídica Virtual, v. 1, n. 8, 2000.

${ }^{15}$ HABERLE, Hermenêutica Constitucional - a sociedade aberta dos intérpretes da Constituição: contribuição para interpretação pluralista e procedimental da Constituição.

16 Ibid.

17 A principal tese da obra de Peter Haberle foi assim articulada pelo próprio autor: "No processo de interpretação constitucional estão potencialmente vinculados todos os órgãos estatais, todas as potências públicas, todos os cidadãos e grupos, não sendo possível estabelecer-se um elenco cerrado ou fixado com numerus clausus de intérpretes da Constituição." (Haberle, 2014, p. 27)

${ }^{18}$ Nesse sentido, assevera: "Do ponto de vista teórico-constitucional, a legitimação fundamental das forças pluralistas da sociedade para participar da interpretação constitucional reside no fato de que essas forças representam um pedaço da publicidade e da realidade da Constituição, não podendo ser tomadas como fatos brutos, mas como elementos que se colocam dentro do quadro da Constituição: a integração, pelo menos indireta, da res publica na intepretação da Constituição em geral é expressão e consequência da orientação constitucional aberta no campo de tensão do possível, do real e do necessário" (Haberle, 2014, p. 38)
} 
Assim, a Corte Constitucional haverá de interpretar a Constituição em correspondência com a sua atualização pública. Ainda assim, há uma constituição material que subsistirá, sem interpretação constitucional por parte do juiz, simplesmente porque poderá não chegar à corte constitucional. Os intérpretes da constituição em sentido amplo desenvolvem, automaticamente, direito constitucional material.

Por essa razão, o referido autor apela à necessidade de se aperfeiçoarem instrumentos capazes de viabilizar o acesso às informações relevantes para o exercício da jurisdição constitucional por parte dos juízes constitucionais. Tal aspecto decorre da necessidade de se conectar a razão interpretativa por parte dos juízes com o desenvolvimento, no âmbito da sociedade, da norma constitucional.

Nesse sentido, o referido autor defende que devem ser aperfeiçoados os instrumentos de acesso por parte dos juízes constitucionais às informações relevantes para a tomada de decisão no âmbito da jurisdição constitucional. Não apenas isso, mas igualmente, devem ser ampliadas as formas de participação no processo constitucional daqueles que, igualmente, são partícipes no processo de interpretação constitucional ${ }^{19}$.

A necessidade de se incrementar essa abertura da jurisdição constitucional se evidencia de forma mais intensa ao se reconhecer, tal como alerta Gilmar Mendes, que é próprio do controle de constitucionalidade o exame dos fatos e prognoses legislativos ${ }^{20}$.

Para que se viabilize o alcance dos fins pretendidos, dois aspectos importantes deveriam ser observados: (i) possibilidade do tribunal se valer de todos os elementos técnicos disponíveis para apreciação da legitimidade do ato questionado; (ii) amplo direito de participação por parte de terceiros (des)interessados.

\footnotetext{
${ }^{19}$ Nesse sentido, assevera: "Para a conformação e a aplicação do direito processual resultam consequências especiais. Os instrumentos de informações dos juízes constitucionais - não apesar, mas em razão da própria vinculação à lei-devem ser ampliados e aperfeiçoados, especialmente no que se refere às formas gradativas de participação e à própria possibilidade de participação no processo constitucional (especialmente nas audiências e nas "intervenções"). Devem ser desenvolvidas novas formas de participação das potências públicas pluralistas enquanto intérpretes em sentido amplo da Constituição. O direito processual constitucional torna-se parte do direito de participação democrática" (Haberle, 2014, p. 46)

${ }^{20}$ A propósito do tema, esclarece Gilmar Mendes: Fato legislativo: todo e qualquer fato real que tenha relevo para aplicação de uma norma. Dividem-se em fatos históricos, fatos atuais e eventos futuros (Mendes, 2000, p. 8)

Mais adiante, esclarece: No que concerne aos eventos futuros, "entende-se que a decisão sobre a legitimidade ou a ilegitimidade de uma dada lei depende da confirmação de um prognóstico fixado pelo legislador ou da provável verificação de um dado evento". (Mendes, 2000, p. 9)
} 
A esse respeito, sustenta Gilmar Mendes, que "a constatação de que, no processo de controle de constitucionalidade, se faz, necessária e inevitavelmente, a verificação dos fatos e prognoses legislativos sugere a necessidade de adoção de um modelo procedimental que outorgue ao Tribunal as condições necessárias para proceder essa aferição." 21

Diante disso, portanto, as audiências públicas surgem como forma de atendimento da necessidade de criação de instrumentos que permitam a abertura da corte para provê-la de meios para a realização das análises relativas aos fatos e prognoses.

\section{Dos pressupostos da legitimidade democrática das audiências públicas}

Conforme acima mencionado e diante da breve exposição acerca dos fundamentos teóricos que levaram ao surgimento das audiências públicas, é possível afirmar que os pressupostos de legitimidade democrática das audiências públicas assentam-se em dois aspectos: (i) necessidade de produção de informações, bem como acesso a essas informações para a qualificação argumentativa da solução desenvolvida pela jurisdição constitucional à questão suscitada; e (ii) pretensão de criação de mecanismo de acesso e participação da sociedade civil na tomada de decisões no âmbito da Corte Constitucional.

A propósito dos pressupostos mencionados, torna-se oportuna a realização de análises específicas.

\subsection{As audiências públicas e a participação da sociedade civil}

O instrumento foi, inicialmente, previsto na Constituição de 1988, notadamente em seu art. 58, que dispõe que às comissões da Câmara dos Deputados e do Senado Federal cabem, em razão da matéria de sua competência, realizar audiências públicas com entidades da sociedade civil. Existe, ademais, regulação na legislação infraconstitucional e no regimento interno de ambas as casas do Congresso Nacional, das regras e procedimentos para a realização de audiências públicas.

\footnotetext{
${ }^{21}$ MENDES, Controle de Constitucionalidade: Hermenêutica Constitucional e Revisão de Fatos e Prognoses Legislativos pelo órgão judicial.
} 
Na Câmara dos Deputados, a realização das audiências públicas está prevista nos artigos 255 a 258 de seu Regimento Interno. Já no Senado Federal, a disposição sobre as audiências públicas engloba os artigos 93 a 95 do respectivo Regimento Interno. Em ambos os casos, o expediente é considerado uma forma das comissões parlamentares instruírem matéria legislativa em trâmite, bem como tratarem de assuntos de interesse público relevante.

No âmbito do procedimento na Câmara dos Deputados, conforme previsto no artigo 255, compete às comissões a determinação da realização de audiência pública com entidade da sociedade civil para instruir matéria legislativa em trâmite, bem como para tratar de assuntos de interesse público relevante, atinentes à área de atuação da respectiva comissão. Poderão propor a realização de audiência pública qualquer membro da comissão ou entidade da sociedade civil interessada. Cabe à comissão, igualmente, a incumbência de selecionar, para serem ouvidas, as autoridades, as pessoas interessadas e os especialistas ligados às entidades da sociedade civil participantes.

Interessante notar que o $\S 1^{\circ}$ do artigo 256 do Regimento Interno da Câmara dos Deputados determina que "na hipótese de haver defensores e opositores relativamente à matéria objeto de exame, a Comissão procederá de forma que possibilite a audiência das diversas correntes de opinião". Da reunião da audiência pública será lavrada ata, que será arquivada juntamente com os pronunciamentos escritos e demais documentos que a instruírem (art. 258).

Igualmente, o Regimento Interno do Senado Federal, em essência, regulamenta a realização das audiências públicas de forma bastante semelhante à Câmara dos Deputados.

No âmbito do Supremo Tribunal Federal, a Lei n ${ }^{\circ}$ 9.868/99 prevê nos $\operatorname{artigos} 9^{\circ}, \S^{\circ}$, e 20. $\S 1^{\circ}$, que "em caso de necessidade de esclarecimento de matéria ou circunstância de fato ou de notória insuficiência de informações existentes nos autos, poderá o relator requisitar informações adicionais, designar perito ou comissão de peritos para que emita parecer sobre a questão, ou fixar data para, em audiência pública, ouvir depoimentos de pessoas com experiencia e autoridade na matéria".

Com norma essencialmente semelhante, a Lei no 8.882/99, que regulamenta a ADPF, prevê a realização das audiências públicas em seu art. $6^{\circ}, \S 1^{\circ}$. Conforme disposto no 
Regimento Interno do Supremo Tribunal Federal, as audiências públicas podem ser convocadas pelo Relator do caso (art. 21, XVII) e pelo Presidente do Tribunal (art. 13, XVII).

De acordo com o artigo 154 do Regimento Interno do Supremo Tribunal Federal, ao Ministro que presidir a audiência competirá a escolha das pessoas que serão ouvidas, divulgar a lista dos habilitados, determinar a ordem dos trabalhos e especificar o tempo disponível para cada uma das manifestações.

De forma semelhante ao previsto no Regimento Interno da Câmara dos Deputados, o inciso II do parágrafo único do artigo 154 prevê que "havendo defensores e opositores relativamente à matéria objeto da audiência, será garantida a participação das diversas correntes de opinião". Encerrada a audiência pública, os trabalhos serão registrados e juntados aos autos do processo, quando for o caso, ou arquivados no âmbito da Presidência.

De início, é de se destacar a ampla discricionariedade do Ministro Relator (ou do Presidente do Supremo, conforme o caso) para o estabelecimento de regras, procedimentos e formas de participação. A seleção de participantes e a definição do modo de manifestação também são discricionárias e não desafiam recursos. A participação poderá se dar como ouvinte, sem direito à manifestação; como colaborador, com o envio de sugestões; como expositor na sessão de realização da audiência, após deferimento pelo ministro que presidir a audiência pública.

Como é de comum conhecimento, não há a previsão de nenhum ônus argumentativo, ou necessidade de referência, relacionado a quaisquer dos trabalhos ou manifestações apresentadas no âmbito das audiências públicas.

No que concerne ao procedimento de convocação das audiências públicas, faz-se referência a interessante pesquisa sobre o tema, realizada por Marjorie Corrêa Marona e Marta Mendes da Rocha, na qual se produziu um levantamento a respeito das audiências públicas ocorridas no Supremo Tribunal Federal entre os anos de 2007 a 2014.

Entre os dados coletados, identificou-se que três justificativas principais foram mais comumente invocadas: (i) a necessidade de se promover "abordagem técnica $e$ interdisciplinar da matéria" para o fim de "esclarecimento das questões de fato pertinentes ao caso"; (ii) o objetivo de analisar as consequências fáticas da legislação discutida e respectivas consequências da decisão que sobre ela recaia; e (iii) o fato de a legislação ou questão discutida revelar efeitos importantes sobre determinados grupos ou for além dos 
interesses manifestados pelos autores da ação constitucional com repercussão em valores fundamentais da sociedade brasileira ${ }^{22}$.

Destacam, as referidas autoras, igualmente, que são recorrentes, nas manifestações dos ministros em audiências, as referências ao incremento da legitimidade democrática viabilizada pelo instrumento utilizado. A esse respeito, concluíram que de oito audiências públicas analisadas, apenas em duas não houve a referência a esse fundamento nas manifestações de abertura e encerramento ${ }^{23}$.

Em que pesem as manifestações em relação ao incremento da legitimidade democrática promovida pelas audiências públicas, concluíram, as autoras em questão, que os ministros presidentes das sessões exerceram relevante controle em relação às exposições. Segundo o referido levantamento, os expositores não seriam inteiramente livres para controlar a agenda e igualmente para dar-lhe o tratamento desejado (Marona \& Rocha, 2017, p. 148).

Comparativamente, concluiu-se que o procedimento adotado nas audiências públicas afastaria a hipótese de que se caracterizariam por procedimentos deliberativos, haja vista as limitações de participação e de interação entre os participantes. Assim, para as autoras em questão, as audiências públicas poderiam ser melhor compreendidas como arguições do que, propriamente, como processos deliberativos ${ }^{24}$.

4.2. As audiências públicas e a produção de informações necessárias para a análise de fatos e prognoses

Em seu clássico artigo - acima já mencionado - a respeito do tema, Gilmar Mendes Ferreira esclarece que fatos legislativos são todo e qualquer fato real que tenha relevância para a aplicação de uma norma, subdividindo-se esses em fatos históricos, atuais e futuros ${ }^{25}$.

\footnotetext{
${ }^{22}$ MARONA, Marjorie Corrêa; ROCHA, Marta Mendes, Democratizar a jurisdição constitucional? O caso das audiências públicas no Supremo Tribunal Federal, Revista de Sociologia e Política, v. 25, n. 62, p. 131-156, 2017.

23 Ibid.

${ }^{24}$ Ibid.

${ }^{25}$ MENDES, Controle de Constitucionalidade: Hermenêutica Constitucional e Revisão de Fatos e Prognoses Legislativos pelo órgão judicial.
} 
Muito embora possa se afirmar que a análise de fatos e prognoses legislativos seja atividade relativamente típica no âmbito da jurisdição constitucional, reputa-se ao famoso caso Müller v. Oregon a característica do pioneirismo concernente à análise dos fatos sob a perspectiva de elementos de natureza científica e sociológica no judicial review.

No caso em referência discutiu-se a constitucionalidade da lei trabalhista do Estado de Oregon, nos Estados Unidos, com fundamento na qual Curt Muller, um empresário do ramo de lavanderia, foi condenado ao pagamento de pena pecuniária em razão de ter obrigado uma empregada a trabalhar mais de dez horas por dia.

O caso se tornou célebre em razão da atuação do advogado Louis Brandeis, que de forma inédita deu ênfase em seu memorial apresentado à Corte, às manifestações de natureza sociológica e médica, relativas ao impacto das longas jornadas de trabalho nas mulheres, em detrimento dos argumentos de natureza puramente jurídica.

A forma de abordagem de Louis Brandeis, no conhecido "Brandeis Brief" foi o precursor da atuação dos amici curiae nas Cortes Constitucionais e, posteriormente, da própria função das audiências públicas quanto ao provimento de informações técnicas relevantes para a tomada de decisões na jurisdição constitucional.

É de se destacar, como bem demonstraram Gilmar Mendes ${ }^{26}$ e Peter Haberle ${ }^{27}$, a necessidade de se prover o Judiciário com informações técnicas relevantes relacionadas aos efeitos concretos da legislação em discussão, das alternativas em jogo e respectivas consequências práticas. A abertura em processos decisórios às informações dessa natureza é fundamental para a qualificação das decisões tomadas, notadamente ao se tratar de decisões sensíveis e de natureza política, na conceituação de Robert Dahl ${ }^{28}$.

Referido aspecto, todavia ressalta a necessidade de se refletir a respeito da delicada questão relativa ao procedimento de coleta de informações a respeitos dos fatos que poderão servir de subsídios para as decisões públicas, notadamente quando se está diante de processos decisórios no âmbito da jurisdição constitucional. De fato, enquanto no âmbito do legislativo a legitimidade das eleições majoritárias são suficientes para validar as decisões

\footnotetext{
${ }^{26}$ Ibid.

${ }^{27}$ HABERLE, Hermenêutica Constitucional - a sociedade aberta dos intérpretes da Constituição: contribuição para interpretação pluralista e procedimental da Constituição.

${ }^{28}$ DAHL, Decision-making in a democracy: the Supreme Court as a national policy-maker.
} 
tomadas pelo quórum constitucionalmente previsto, sem maiores necessidades de subsídios argumentativos, no Judiciário impõe-se relevante ônus argumentativo consubstanciado no dever de fundamentação das decisões (art. 93, IX, da Constituição Federal).

Diante disso impõe-se a necessária reflexão a respeito da delicada questão relativa ao procedimento de coleta de informações sobre os fatos que serão apresentados para subsidiar e/ou fundamentar as decisões tomadas no âmbito da jurisdição constitucional.

Sobre esse problema, foi julgado na Suprema Corte americana o caso Daubert $v$. Merrell Dow Pharmaceuticals, 509 U.S. 579 (1993). Nesse caso foram estipulados os padrões para a admissão de "expert testimony" nas cortes federais, ao que se denominou de "Daubert standard"

Jason Daubert e Eric Schuller nasceram com deficiências de muita gravidade. Sob a alegação de que o medicamento Bendectin teriam causado as deficiências verificadas, os pais das crianças ajuizaram uma ação contra Merrell Dow Pharmaceuticals Inc.

Daubert e Schuller, no âmbito do processo em referência, apresentaram provas produzidas por conta própria que fundamentariam as referidas alegações. As provas apresentadas eram lastreadas em estudos com animais "in vivo" e "in vitro", estudos farmacológicos e na reanálise de outros estudos publicados. Ocorre que as metodologias empregadas ainda não haviam sido aceitas no âmbito da comunidade científica em geral.

Os parâmetros utilizados para a rejeição das provas resultaram na atualização da Federal Rules of Evidence (1975). Pela norma em questão, a testemunha seria qualificada como especialista pelo conhecimento, habilidade, experiência, treinamento ou educação, de modo a estar apta a manifestar opinião técnica apenas se atendidos, cumulativamente quatro critérios, quais sejam: (i) o conhecimento técnico, científico ou especializado permitiria ajudar na compreensão a respeito da prova ou para determinar o fato em questão; (ii) o testemunho é fundamentado em fatos ou dados suficientes; (iii) o testemunho é resultado da aplicação de princípios e métodos confiáveis; (iv) o especialista aplicou de conforma confiável os princípios e métodos ao caso em questão.

O caso Daubert estabeleceu um checklist para o julgamento realizado com fundamento em depoimentos científicos de especialistas que poderia ser sistematizado da seguinte forma: (i) se a técnica ou a teoria pode ou já foi testada - ou seja, se a teoria do especialista pode ser desafiada objetivamente ou se se trata, apenas, de conclusão subjetiva que não pode ser 
racionalmente alcançada confiavelmente; (ii) se a técnica ou a teoria foi submetida à revisão por partes e publicações; (iii) a potencial ou factual taxa de erro da técnica ou da teoria quando aplicada; (iv) a existência ou a manutenção de padrões de controle; (v) se a técnica ou a teoria foi aceita pela comunidade científica em geral.

Outros critérios também foram introduzidos por precedentes nos EUA para se estabelecer a validade do depoimento dos experts nas cortes norte-americanas. A propósito, podem ser suscitados: (i) se os especialistas estão se propondo a testemunhar a respeito de temas natural e diretamente decorrentes de pesquisas que eles conduziram independentemente do litígio ou se eles desenvolveram as referidas opiniões expressamente para os fins de testemunhar (Daubert v. Merrell Dow Pharmaceuticals, Inc. 1995); (ii) se os especialistas injustificadamente extrapolaram de uma premissa aceita para uma conclusão infundada; ou, ainda, se há uma omissão analítica relevante entre os dados e a opinião proferida (General Elec. Co. v. Joiner, 1997); (iii) se o especialista adequadamente considerou explicações alternativas óbvias (Claar v. Burlington, 1994 e Ambrosini v. Labarraque, 1996); (iv) se o especialista está sendo cauteloso como se estivesse no exercício regular de sua profissão alheia à consultoria remunerada para o litígio (Sheehan v. Daily Racing Form, Inc.1997 e Kumho Tire Co. v. Carmichael, 1999). Exige-se, a propósito, que o especialista empregue na Corte o mesmo nível de rigor intelectual que caracteriza a prática de um especialista em seu campo relevante; (v) se o campo em que o expert alega ser especialista é conhecido por alcançar resultados confiáveis para o tipo de opinião proferida pelo expert. (Kumho Tire Co. v. Carmichael, 1999; Moore v. Ashland Chemical, Inc., 1998; Sterling v. Velsicol Chem. Corp., 1988). ${ }^{29}$

Verifica-se assim que, para o efetivo cumprimento da função informativa como fator de habilitação técnica das decisões do Supremo Tribunal Federal, é necessária a qualificação das informações produzidas e que subsidiam as decisões. A esse respeito, como se pode verificar a partir da experiência norte-americana, a qualificação da informação é realizada por critérios de validade de natureza epistêmica. Muito distinto, portanto, no que concerne 
ao cumprimento dessa importante função, de critérios de legitimidade participativa, baseados na necessidade de se promover ampla participação da sociedade civil.

Assim, como bem observam Leal, Herdy e Massadas, a qualificação da informação pressupõe o envolvimento do tribunal na desafiadora tarefa de estabelecer critérios objetivos para discernir informação confiável de informação não-confiável ${ }^{30}$.

De fato, a mera produção de informações e dados, de toda natureza, com duvidosa fundamentação principiológica e metodológica pode - sob perspectivas de natureza técnico/científica - deslegitimar a análise de fatos e prognoses legislativos. Trata-se portanto, de alcançar resultados absolutamente opostos aos pretendidos com a realização das audiências públicas.

\section{Conclusão}

Em perspectiva idealizada, Robert Dahl defende que o processo democrático é, pelo menos, caracterizado por cinco critérios, quais sejam: a) efetiva participação, que é identificada pela igual e efetiva oportunidade de que dispõem todos os partícipes de terem suas posições conhecidas pelos demais; b) igualdade de voto, consubstanciada na igual oportunidade de voto no momento da tomada de decisão, que deverá ter o mesmo peso para todos; c) compreensão esclarecida, caracterizada pela igual e efetiva oportunidade de conhecimento por todos, dentro de certos limites de tempo, das alternativas e respectivas consequências relevantes; d) controle da agenda, a ser verificada pela oportunidade de controle por parte dos membros, de quais matérias serão decididas e a respectiva forma de decidir; e) inclusão de adultos, vislumbrada pela titularização, por parte de todos os adultos, de todos os direitos dos cidadãos decorrentes dos quatro critérios anteriores ${ }^{31}$.

É importante reforçar que os critérios suscitados por Dahl são de natureza idealizada, ou seja, não podem e não devem ser considerados como critérios práticos e ao mesmo tempo absolutos, de forma que se os compreenda como condições sine qua non para verificação da legitimidade democrática de determinado processo decisório. Robert Dahl, aliás, reforça que

\footnotetext{
${ }^{30}$ LEAL; HERDY, Uma década de audiências públicas no Supremo Tribunal Federal (2007-2017).

${ }^{31}$ DAHL, Decision-making in a democracy: the Supreme Court as a national policy-maker.
} 
em toda e qualquer relevante instituição democrática é possível a identificação de déficits relacionados ao pleno preenchimento dos critérios acima especificados ${ }^{32}$.

A realidade, de fato, pode não corresponder, exatamente, ao esquema teórico-abstrato elaborado de forma apriorística e distante da pluralidade de circunstâncias e variáveis encontradas na vivência prática. Ainda assim, não se pode negar a utilidade da sistematização de Dahl, se se pretende desenvolver avaliações e diagnósticos com o objetivo de aprimorar a legitimidade democrática de determinados processos decisórios.

Realizadas tais considerações, pode-se afirmar que os referidos critérios - embora não absolutos e definitivos - podem se revelar úteis para a avaliação da validade da premissa de que as audiências públicas conferem legitimidade democrática ao processo decisório da jurisdição constitucional. Não resta dúvidas de que a audiência pública é um instrumento de participação da sociedade civil nas decisões políticas.

Não é possível, todavia, associar a possibilidade de participação da sociedade civil em audiências públicas com a garantia da legitimidade democrática das decisões proferidas no âmbito da jurisdição constitucional. De fato, muito embora os critérios apresentados por Robert Dahl não sejam propriamente aplicáveis aos procedimentos de realização das audiências públicas, porém é possível deles extrair algumas reflexões importantes.

Inicialmente, há que se destacar que não há qualquer garantia de participação efetiva. A participação e o modo de participação são definidos discricionariamente pelo ministro presidente do ato. Não há, outrossim, igualdade de participação por voto - e é da essência da jurisdição que assim não seja, a não ser em casos específicos, com regras próprias, como acontece nos casos de júri.

Da mesma forma, no que concerne à compreensão esclarecida, nota-se, inclusive, que no próprio Supremo Tribunal Federal a disseminação da informação produzida depende da discricionariedade dos próprios integrantes da Corte. A agenda também não é submetida ao controle democrático; os próprios membros da Corte decidem quais matérias se submeterão ao procedimento e de que forma este se realizará.

Conclui-se portanto, que ainda considerando importante a viabilização da participação da sociedade civil, não é possível inferir que as audiências públicas poderiam ser valoradas 
como forma de se garantir a conexão do tribunal com as decisões democráticas de natureza majoritária. Diferentemente, o critério de legitimação das audiências públicas pode estar relacionado aos próprios argumentos que fundamentam a jurisdição constitucional, em toda a sua extensão.

Pelos mesmos motivos, portanto é possível concluir que as realizações das audiências públicas não são aptas a endereçar, propriamente, respostas adequadas às críticas formuladas (conforme as críticas de Jeremy Waldron, acima sintetizadas).

De outro lado, também é importante o reconhecimento da utilidade do instrumento para produzir e viabilizar o acesso a informações relevantes para a prolação das decisões tomadas na jurisdição constitucional, mormente quando se trata de questões sensíveis, com diversas alternativas razoavelmente possíveis (hard cases), que poderão ter importante impacto na sociedade.

Ocorre que, no entanto, se essa é a função predominante que justifica a legitimidade do emprego das audiências públicas, são necessárias as reflexões acerca da qualificação das informações que constituem o objeto das audiências públicas.

Não é razoável, v.g., supor que informações de caráter subjetivo - fundamentadas em princípios e métodos de caráter valorativo - mereçam a mesma consideração, na jurisdição constitucional, que estudos técnicos fundamentados em premissas científicas, com o específico propósito de evidenciar causas e efeitos em relação às consequências práticas e correlações com possíveis decorrências jurídicas das decisões a serem adotadas.

Ao contrário, se a jurisdição constitucional encontra-se aberta a essa ponderação valorativa que permite situar em um mesmo locus deliberativo, argumentos de natureza e origem principiológica diversa e pluralista, talvez esteja autoritariamente avançando, de forma antidemocrática, nas funções do Poder Legislativo.

\section{REFERÊNCIAS}

BARROSO, L. R. A razão sem voto: o supremo tribunal federal e o governo da maioria.

Revista Brasileira de Políticas Públicas, v. 5, n.2010, p.23-50, 2015.

DAHL, Robert A. Decision-making in a democracy: the Supreme Court as a national policymaker. Journal of Public Law, v.1, p.279-295, 1957. 
HABERLE, P. Hermenêutica Constitucional - a sociedade aberta dos intérpretes da Constituição: contribuição para interpretação pluralista e procedimental da Constituição. DPU, v.60, 2014.

LEAL, Fernando; HERDY, Rachel. Uma década de audiências públicas no Supremo Tribunal Federal (2007-2017). Revista de Investigações Constitucionais, v.5, n.1, p.331-372, 2018.

MARONA, Marjorie Corrêa; ROCHA, Marta Mendes. Democratizar a jurisdição constitucional? O caso das audiências públicas no Supremo Tribunal Federal. Revista de Sociologia e Política, v.25, n.62, p.131-156, 2017.

MENDES, Gilmar Ferreira. Controle de Constitucionalidade: Hermenêutica Constitucional e Revisão de Fatos e Prognoses Legislativos pelo órgão judicial. Revista Jurídica Virtual, v.1, n.8, 2000.

SEIDMAN, Louis Michael. The Secret Life of the Political Question Doctrine. The John Marshal Law Review, v.37, p.441-480, 2004.

WALDRON, J. The core of the case against judicial review. Yale Law Journal, v.115, p.1346-1360, 2005. 